\title{
Hearing Knowledge into Action: Mobilizing Sound for Multicultural Imaginaries
}

\author{
Candance Doerr-Stevens \\ University of Wisconsin, Milwaukee \\ U. S. A. \\ Molly Buckley-Marudas \\ Cleveland State University \\ U. S. A.
}

ABSTRACT: Drawing on multimodal, sound-based data, this study examines how high school students harnessed elements of sound and music for multicultural learning within collaborative research and radio podcasting. Data were collected from a variety of sources, including field notes, final media projects, and audio and video footage of students' collaborative media production processes and interviews. Findings reveal multivocal and divergent engagements in the sound editing process as well as multimodal struggles in which students leveraged sound to express nuanced views about racism, culture, and privilege. This study has implications for educators teaching multicultural perspectives and critical media literacy studies.

KEYWORDS: critical media literacy, digital media production, multimodality, sound design, sonic landscapes

Multimodal Spaces for Multicultural Learning Methods of Inquiry

Findings: Collaborative Struggle with Sound

Discussion: Sonic Landscapes for Cultural Dexterity

Conclusion

References

Author Contact

It [racial injustice in schools] is not something that we can actually answer. There are some things in the world that we will never know. We will never actually answer the question because there is so much variation, but we must figure out how to work around and with it.... If we made them [my classmates] think, I have succeeded in my documentary.

In the quotation above, Erin, a high school junior, describes her experiences and hopes for producing a radio documentary that examines racial stereotypes around academic achievement. A high-achieving African American female, Erin, regularly enrolls in International Baccalaureate (IB) level courses at her school and notes that most of her classmates in the IB classes are White. A classmate, Mahmud, a first generation immigrant from Somalia, also states his desire to enroll in IB classes yet notes that many of his classmates do not take school seriously. 
Rowan, a senior who identifies as biracial and does not enroll in IB classes, notes that students in these higher level classes can sometimes "get attitudes" or look down upon those not in the higher level classes. Further exploring the impacts of school tracking systems, Erin also describes several occasions in which teachers and administrators have exercised low expectations of her academic abilities for reasons she believes have to do with her skin color. Erin goes on to state that these occasions have caused her to second guess herself and her abilities, an experience not uncommon for linguistically diverse students and students of color (Ladson-Billings, 2009; Liou, 2016).

Fortunately for Erin, Mahmud, and Rowan, their school schedules intersected for a single English course in which they were required to create a radio documentary about a social issue of their choosing. Given their personal experiences and interests in school tracking or other ability grouping systems, Erin and her group members chose to investigate the racial stereotypes related to school achievement. Creating a radio documentary, however, required different types of research. Students had to interview and record the voices, views, and correlated sounds of community experts. They had to harness sound editing software to combine elements of music, sound effects, dialogue and silence. This multimodal research led Erin and her classmates to compose multi-layered, soundbased texts in the form of radio documentaries. As we shall present below, these sensory-based forms of sound and music forged spaces for exploration and interrogation of various cultural and racial stereotypes in ways that speech or writing alone could not.

Unfortunately, these auditory-rich experiences are often dismissed as mere enhancements to communication and outside the content realms of academic learning. We agree with Mills, Unsworth, and Exley (2018) that the "human senses have always been vital to literacy practices but are seldom acknowledged within studies in education" (p. 26). Researching closely the collaborative sound production processes of high school students, we have documented elsewhere that school-based media production is messier and more conflicted than final products may suggest, especially when identities and social issues are represented via the unseen elements of sound effects, music, and speech (DoerrStevens, 2015; Buckley-Marudas, 2016a). Nevertheless, we approach this work with a deep belief that the messy and conflicted moments hold great potential for fostering young people's critical imaginaries, or as Erin states above, "a how to work around and with it." Instead of dismissing sound as extra curricular, we investigate here the multimodal potentials of sound as important representational spaces for students to struggle with meaning, stance, and truth, while simultaneously producing their own knowledge. Two questions guided this study: (a) How might the production process of sound-based texts such as radio documentaries open new spaces to research and interrogate socio-cultural issues, and (b) In what cases does sound allow critical revision around narratives of identity, community and culture?

To contextualize this study, we foreground the communicative potentials of sound within multimodal composition and critical digital literacy. To begin, we 
explore current frameworks and research for multicultural learning as critical, pluralist practice. Next, we explore the potentials of critical media literacies for multi-vocal inquiry and expression. Then, we explore the current research surrounding the uses of sound and music production for learning. Through reviewing these frameworks, we hope to deepen understandings of the potentials of sound for both multicultural and critical literacy learning. We next present microanalyses of classroom-based sound design, in which high school students work collaboratively to compose with sound as part of the school-sanctioned curriculum. Key sound ensembles are featured to illustrate the potentials of sound to foster small movements of social assertion and conceptual struggle. Finally, we close with considerations for future research surrounding sound as an expressive, critical mode of communication for re-imagining classroom spaces.

\section{Multimodal Spaces for Multicultural Learning}

Critical dialogue and action toward equity, diversity, and social change have long been among the goals of a multicultural education (cf. Darder, 1991; LadsonBillings, 2009; Nieto, 1992; Sleeter, 2005). Such goals, however, are not easy to achieve. Several critiques have been raised against simplistic applications of multicultural education that codify culture to static celebrations of food and holidays (Sleeter, 2018) or dilute multicultural approaches in attempts to make them "palatable" for White middle class audiences (Case \& Ngo, 2017). Pushing beyond a stance of cultural diversity and respect, Culturally Sustaining Pedagogy (Paris \& Alim, 2014) claims that cultures are not only diverse but also dynamic and multidirectional in their outcomes. In this sense, the cultural practices of language, race, and class are not singular and pure in their meaning and impact. Rather, they are in fluid relationship with each other and demand considerations for variegated identities and complex contexts. Wearing multiple identities within complex situations is a daily requirement for both teachers and learners in classrooms, yet access to such versatile mindsets and ways of being are compromised by singular definitions of academic achievement that still flourish within our schools. Paris and Alim (2014, p. 91) claim that such variegated ways of being require a "cultural dexterity" that needs modeling and sustenance.

Similar to Anzaldua's (1987) notion of the borderlands mestiza, which presents identities as simultaneous entities that move fluidly across cultural spaces, the social dexterity of Culturally Sustaining Pedagogy (CSP) also demands a tolerance for contradictions. This intentional hybridity, or mestiza, foregrounds a duality that embraces both the here and there of social situations. For some, a sense of cultural dexterity is achieved through narrative. Building on the Chicana feminist work of testimonio (cf. Latina Feminist Group, 2001), Ashmawi, Sanchez, and Carmona (2018) position the processes of narration and storytelling as acts of weaving that bring together the here and there, to compose multi-voiced texts. Embracing these practices of cultural dexterity and mestiza fluidity, CSP calls upon schools to be spaces for "diverse, heterogeneous practices 
to reimagine the possible" (Alim \& Paris, 2017, p. 3). In other words, how might classrooms and their related curricula invite opportunities for cultural agility and multivocal narrations that promote dialogue and social change?

\section{Multivocality of Multimodal Composition}

Speaking to the need for multivocal narration and dialogue, there exists much research exploring the expressive capacities of multimodality to convey variegated meanings (Bezemer \& Kress, 2008; New London Group, 2000; Ranker, 2014). Viewing each mode of media (sound, visual, voice over, interview dialogue, etc.) as a "voice" or social perspective in itself, Nelson and Hull (2008) describe multimodal texts such as digital stories and other media texts as housing conflicted positions or conflicting voices, a notion Soep (2006) describes as "crowded talk" (p. 201). A growing number of studies have focused specifically on the affordances of multimodality as a space for critical engagement and social struggle (DoerrStevens, 2016; Buckley-Marudas, 2016b; Wohlwend \& Lewis, 2011).

Santo (2013) in particular has suggested that such multimodal, digital spaces promote "hacker literacies," a set of practices that help an individual to become empowered in relation to participatory digital media, such that the social design and norms of digital spaces and their related texts are not ignored or taken for granted. In other words, multimodal expression and the digital platforms where they are published can be seen as malleable avenues for expression of the values and agendas of individual users (p.199). In this sense, the participation practices associated with digital media texts and their associated online spaces are seen as more situational and open to revision, a condition that might possibly invite a hybridity and dexterity of social practices.

Placing such critical potentials within school contexts, some have even suggested that critical media composition practices such as documentary filmmaking and music production redefine understandings of cultural capital and academic rigor (Brader \& Luke, 2013; Dockter, Haug \& Lewis, 2010). In turn, these sensory and arts-based practices have the potential to invite more pluralist forms of participation, which have been shown to forge new pathways for minoritized youth to build the "sociopolitical consciousness" needed to mobilize communities (Ngo, Lewis, \& Maloney Leaf, 2017) and foster civic imaginations (Jenkins, 2018).

While it is promising to illustrate what some are calling "critical digital literacies" (Ávila \& Pandya, 2013), most studies emphasize visual modes as the prominent, organizing forces within a narrative (Mills et al., 2018). Indeed, a focus on the visual is integral to discussions of cultural expression and multimodal composition, especially as classrooms increasingly integrate media texts into the curriculum. That said, we must also attend to the representational impacts of sound, not as supplementary modes, but as potent and plural forces of their own. 


\section{Sonic Landscapes for Learning}

A growing body of work examines the learning potentials of composing with music and sound and the sonic texts such composing creates. Described by some as "sonic landscapes" (Chignell, 2009; Todorova, 2015), these sound-based texts weave together several sounds into texts that convey multi-layered meanings and textures of a specific event, space, or place. Approaching music and sound from a multimodal composition approach, many researchers have discussed the impact of sounds as distinct elements of a text.

Van Leeuwen (1999), for instance, argues that the sound element of music influences meaning by impacting the "modality" or "degree of truth" (p. 156) expressed by a speaker or author. Because of its impact on perceptions of truth and credibility, several scholars of rhetoric and composition have argued that sound be reinstated into composition classes alongside print and visual modalities (Ahern, 2013; Selfe, 2009). This increased emphasis on sound has spawned various explorations of how to study and teach sound as text or address what some call "sonic literacy" (Comstock \& Hocks, 2006, frame 3).

Studies of youth radio in particular have described the potentials of sound and music as unique platforms for youth to speak their own truths while also challenging already existing truths (cf. Chavez \& Soep, 2005; Green, 2013). Building on the history of community radio as a vehicle for civic engagement, Green (2016), in particular, found that radio-based discussion and research invited a more multi-voiced approach to interrogate issues. Green presents the practice of "air-shifting" to describe how, when composing content for radio, youth harness the power of sound and dialogue in radio for collective questioning and critiquing of socio-political discourses (p. 195).

Alongside the small set of studies showcasing the pluralistic potentials of radio, sound, and music, there is a growing presence of sound studies within education looking at the multidirectional learning and embodied experiences of sonic composition (cf. Ceraso, 2014; Gershon, 2017). Teacher education in particular has begun to explore the multivocal potentials of sound. Brownell and Wargo (2017), for instance, examined the use of sound when working with prospective teachers. Aiming to have the prospective teachers critically engage with the neighborhoods of their fieldwork locations, teachers were asked to listen for and record elements of neighborhood, culture, and community. In these pedagogical situations, sound provided a socially situated space to "(re)educate the senses towards multiculturalism" (2017, p. 1).

With increasing attention toward the multivocal potentials of multimodal composition, and of sonic expression in particular, questions arise as to how sound elements provide vehicles for exploring identities and spaces poised for multicultural learning. More specifically, how do sound elements interact in collaborative, school-based contexts, where academic and cultural identities overlap? 


\section{Methods of Inquiry}

To explore these questions, this qualitative study gathered various descriptive and multimodal data from a yearlong study focusing on students' engagement and social struggle with digital media composition. The study was based in a racially and ethnically diverse public high school, situated in a large, Midwestern city in the United States. At the time of this study, the school served approximately 2,200 students and was viewed as one of the best public schools in the city, based on offerings of International Baccalaureate (IB) courses and national report card rankings. While the school was known in the city as an IB school, not all students that attended the school enrolled in IB courses. The school offered courses at three levels that the students referred to as "regular," "honors," and "IB" classes.

Table 1

Focal Research Participants

Name: Race/ethnicity/sex: Role/Grade: Relationship to media production process:

Erin African American female $11 \quad$ Media = Making People Think

If we made them [the audience] think I have succeeded in my documentary... I'm thinking about the people who make themselves blind to the issue. ... it /the documentary] will be the thing that will want to make kids take action by seeing how the stigma [of race] has affected people positively and negatively.

Mahmud African Immigrant male

Rowan

European American and Native American (self-identifies as both white and sometimes biracial) male
11

12

(1)

Media $=$ Another Opportunity to Do Well in School Some kids let the pressure of friends and society get to them. They don't know the benefits that the IB classes can give you. They can help you with college ... most of the people who influence me have been through this, and they tell me not to pay attention to the pressures. They tell me that I am here just to get an education and then get out of here.

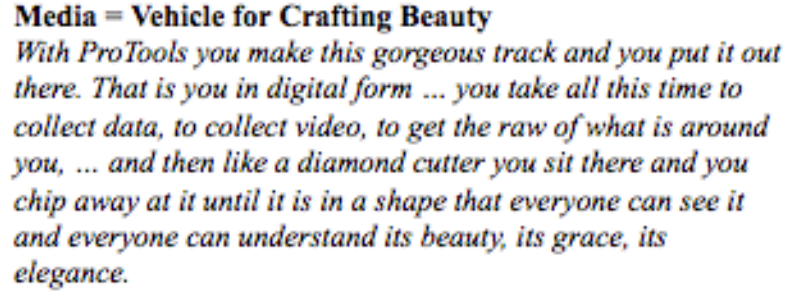
there. That is you in digital form ... you take all this time to collect data, to collect video, to get the raw of what is around you, ... and then like a diamond cutter you sit there and you chip away at it until it is in a shape that everyone can see it and everyone can understand its beauty, its grace, its elegance.

\footnotetext{
* All names are pseudonyms
} 


\section{Participants, Contexts and Curricula}

We used purposeful sampling (Patton, 2001) to select the school context. The school and two classrooms were selected because there was evidence that instructors were intentionally integrating sound and multimodal composition into the curriculum. The participants for this study included 60 junior and senior students, the last two years of secondary school. The students enrolled in two sections of an English course that focused on analyzing nonfiction through radio and film documentary. The course attracted a wide range of students, with varying academic skill levels and ethnic backgrounds. Although not an IB course itself, the English class was one of the few course offerings at the school that enrolled "regular," "honors," and "IB" students, creating a class mix that teachers described as more representative of the school as a whole.

Focal participants for the study consisted of five media production groups in each class, 10 groups overall. While several of the focal production groups provided data of interest for considering multimodal composition with sound, this article focuses on the composing practices of one group in particular, Rowan, Erin, and Mahmud. This group was selected because of the critical nature of the topic they chose to explore, the diverse viewpoints on the issue each participant represented, and the explicit efforts toward collaborative composition and deliberation of ideas that the group exhibited. See Table 1.

\section{Data Gathering and Analysis}

Over the course of a full 40-week school year, I, the first author, attended class a minimum of two days per week. Engaged as a participant observer (Kawulich, 2005), I worked alongside students throughout various media composition projects. I collected data from observation field notes, audio and video recordings of collaborative work sessions, artifact analysis, and interviews with teachers and student participants.

Given the study's focus on social struggle as it occurred amid the process of multimodal composition, this research utilized an action-based framework that draws on the analysis of activity afforded by Mediated Discourse Analysis (cf. Norris \& Jones, 2005; Scollon \& Scollon, 2003; Wohlwend, 2009). Like critical discourse analysis, which emphasizes the social practices and performances enacted via discourses, Mediated Discourse Analysis emphasizes the actions performed with objects and other mediational means, in this case sound.

Based on Wohlwend's (2009) filter approach for Mediated Discourse Analysis, the data were analyzed in four phases. The first and second phases involved transcribing and coding the collaborative work sessions and interviews. These coded transcripts were then reviewed in order to locate the mediational 
means and events, and to identify the key participants. It was during these first two phases that Erin, Mahmud, and Rowan were identified as focal participants and that composing transitions within the radio documentary were identified as the key moments of social and representational struggle. The phase three involved identifying moments during the production process that challenged social practices as they normally occur in classrooms. The phase four involved close analysis of the mediated actions. Given the current study's focus on sound, the phase four analysis involved a track analysis, inspired by Hull and Nelson (2005), of specific transitions within the radio documentaries. The micro-analysis of these moments made visible the interaction of specific sound elements as they were used by different participants in different ways.

\section{Findings: Collaborative Struggle with Sound}

In several instances throughout the school year, the use of collaborative sound and media composition provided spaces for youth to engage with social and cultural issues in ways that provided multivocal expression, peer-to-peer deliberation, and social assertion. These findings are detailed elsewhere (cf. Doerr-Stevens, 2016; Buckley-Marudas, 2016b). When focusing specifically on affordances of sound design, however, we observed several ways in which the combining of different sound elements into sonic ensembles allowed for a sonic simultaneity of representation and engagement with ideas. For purposes of illustrating this dialogic engagement, we focus on two transitions, or sound ensembles, that illustrate the multivocal potentials of sound. Both sound ensembles and their contexts of composition come from the student-produced documentary Racial Discrepancies, a 7-minute radio documentary/podcast exploring how race and ethnicity impact students' academic course selections.

Three high school students, Erin, Mahmud, and Rowan (see also Table 1), worked together in class over a period of six weeks to research, produce, and edit the radio documentary. Although several transitions or sound ensembles were crafted throughout Racial Discrepancies, each requiring several decisions and shaping sound in different ways for different purposes, this article will feature only two due to space constraints; however, the full podcast, with names muted, is available for listening at https://tinyurl.com/y8jepszf.

The first sound ensemble to be addressed foregrounds sonic assertions that allow for pluralistic representations of self. The second ensemble foregrounds the proliferation of multiple purposes occurring simultaneously.

\section{Sound Ensemble 1: Sonic Investigations of School and Neighborhood}

This particular ensemble illustrates how sound elements were harnessed to orient attention away from or towards specific interpretations. This sound 
ensemble occurs one minute and 30 seconds into the 7-minute podcast. Although this same sound ensemble has been discussed in other articles for its strategic use of sound to recruit and maintain audiences (Doerr-Stevens, 2017), it is used here to illustrate the social and interpretive struggles that can occur in collaboratively composed media in school contexts. In an attempt to make visual the workings of sound, Figure 1 illustrates a track analysis of the ensemble showing the distinct sound elements.

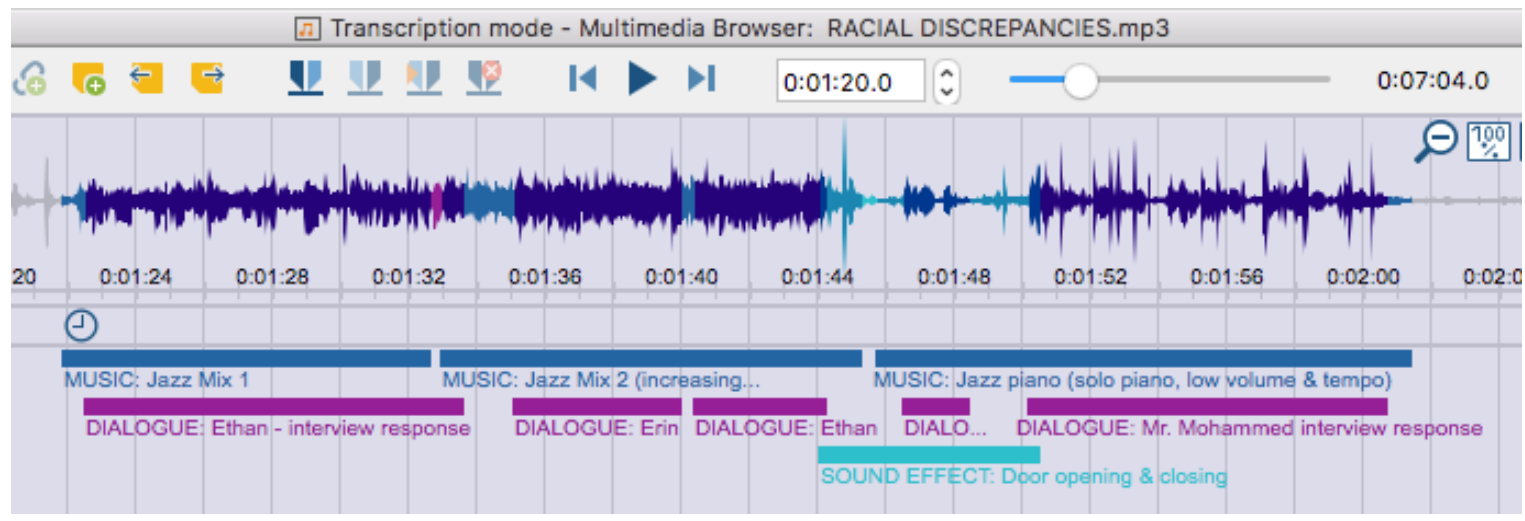

Figure 1: Sound ensemble \#1 representing multiple peer perspectives (This figure illustrates the various layers of sound and music being used in a single transition of radio documentary).

At this moment, the radio documentary is shifting from one key piece of interview dialogue to another through deliberate positioning of three different sound elements: dialogue (interview dialogue and voice-over narration), music, and sound effects. In this particular transition, Erin interviews a fellow classmate, Ethan, a White male who has been taking advanced-level, International Baccalaureate (IB) classes for three years. In dialogue preceding this transition, Ethan has shared that he takes IB classes because the people in these classes share his "worldview." Erin, who is also enrolled in several IB classes, prompts Ethan to explain how he knows that his classmates share his worldview. Ethan replies with confidence, "Well, I mean, yeah, this is my third year taking IB or IB prep classes."

Layered alongside the dialogue are two additional sound elements: a sound effect of a door opening and closing, and jazz music that increases in volume as the interview dialogue of Ethan plays (see Figure 1). Occurring simultaneously, the sounds may merge together in a way that seems harmonious, representing group consensus and agreement with Ethan's comment. Through comparative analysis of collaborative work transcripts and individual interviews, however, this sound ensemble emerges as a space of social struggle among the group members, where each participant harnesses a different sound element to express different perspectives on the issue. 
For Rowan, who selected the music for this moment, the editing was an issue of "protecting the work." When asked about this specific sound transition in a post-production interview, Rowan describes the use of jazz music as a way to "keep the mind active" while listening to the piece. When further probed to explain why he selected jazz music for this particular moment, Rowan admits that he dislikes Ethan, the person who is being interviewed in this transition, and that he thinks Ethan sounds "very arrogant." Rowan goes on to explain that he does not want to offend or "aggravate our listeners." Hoping to keep his classmates listening, he states that he added the jazz music as a way to "soften the mood."

In addition to the jazz music selection for this sound ensemble, Rowan also adds a sound effect of a door opening and closing. Positioned as a sonic segue, this sound effect connects the end of one dialogue interview clip with Ethan to the beginning of a new dialogue interview clip with Mr. Mohammed, an elder at a local faith-based community center. Mahmud chose to interview Mr. Mohammed because of the important role he plays in the teaching and learning within his family's faith community. In this interview clip, Mr. Mohammed states that "race does not matter in students' class selection," but rather that parents have more influence on these decisions.

When asked to explain why the door sound effect is placed in between the interview clips of Ethan and Mr. Mohammed, Rowan explains that the sound of the door opening and then closing simulates the feeling of "students coming into class just as a teacher is about to begin speaking." Rowan knows that most of his classmates, other than Mamud, will not know Mr. Mohammed, yet he wants to create anticipation for what Mr. Mohammed has to say. In using the door sound effect, Rowan states that it "begins to position him [Mr. Mohammed] as a leader." In this single transition Rowan uses the jazz music to soften the delivery of Ethan's perspective while also using a door sound effect to emphasize the perspective of Mr. Mohammed. In both cases, sound is used to shift and complicate the meaning and mood of the dialogue clips in ways that challenge what is represented by the words alone.

For Mahmud, the selection of sound effects and music in this particular ensemble was not a site of representational struggle. In fact, in post-production interviews he states that the sound effects "go with the music." When asked what his views are on this particular transition, Mahmud is quick to admit that some will agree with the views presented by Ethan, the White male subject in the documentary, and others will not. Rather than being offended by Ethan's interview responses, Mahmud describes Ethan as unaware of "minority perspectives" on the issue.

While Mahmud was not as conflicted about the sound selections in the first part of this ensemble, he was very invested in the second part, which features the interview dialogue of Mr. Mohammed, a leader from his personal faith community. According to Mahmud, the interview dialogue with Mr. Mohammed emphasizes the importance of "family background" in academic choices, a perspective Mahmud feels strengthens the documentary through representing "multiple perspectives" on education and specifically how he views the issue. In a post-production 
interview, Mahmud describes his own family as being "really strict" about education and "you either get an education or you don't," and if you don't then "you're not part of the family." For Mahmud, the inclusion of Mr. Mohammed's dialogue clip describing the impact of family helps to present his position on the issue: that family, not race, impacts course selections.

For Erin, the sound editing decisions surrounding the Ethan interview were more conflicted. While most of the sound editing in the radio documentary was executed with Rowan's hands at the computer, Erin and Mahmud worked closely with Rowan throughout the editing process, often sitting at his side, listening with headphones, and discussing sound options as a group. For this particular ensemble, Erin discloses a deep investment in the sound decisions. When asked in a post-production interview about this transition, Erin states that she directly intervened on the sound editing and purposely increased the volume levels of the jazz music at this moment. She describes her sound-editing decision as "protecting a friend." As she describes,

I remember turning up the volume at the end of this sentence [interview clip of Ethan] so that you really couldn't hear, just in that one spot. So you could mask the end of the sentence. I did it more to protect him (Ethan), because we are friends and you don't want to present your friends in a bad light.

From Erin's perspective, it is the volume of the music, not the jazz genre, which is harnessed as a mediational means to shift focus away from potentially negative interpretations of the interview dialogue. Instead of trying to soften the tone, as Rowan had intended with the jazz, Erin increases the volume, intending to "mask" the content of the dialogue. She also does this to distance herself from the delivery of what she feels is a stereotypical representation of ideas.

Erin's editing decisions in this particular ensemble reveal that she is conflicted by the representation of ideas in this ensemble. On the one hand, she feels that Ethan is not acknowledging the full range of worldviews represented in the IB classes they both take, specifically those of her own, and so she asks him to clarify. On the other hand, she and Ethan are friends and she does not want to damage that relationship. In this case, a manipulation of sound allows her to maintain her stance in both the here and there of her social positioning, in that she is both an IB student and an African American female with worldviews different from Ethan's

Beyond this single transition, Erin voices her discontent with the media product as a whole. In a post-production interview, Erin shares that she hoped her radio documentary would offer a more complex understanding of race and academic choices. Instead, she feels that it reproduces "common or stereotypical" understandings. Still, she maintains hope that it will probe her peers to think about the issue.

Just as Rowan aligns himself with the jazz music, and Mahmud aligns himself with the Mr. Mohammed interview clip, Erin also aligns herself with a specific sound element, one that allows her a space to take a stance on the complicated issue. These diverse attachments to sound reveal the students' 
desires to stay engaged with the issue, even if consensus cannot be reached. Much like Santo's (2013) discussion of hacker literacies, the multimodal capacities of sound design allowed students to forge a relational stance with the issue or "hack" their ways into a contested space.

\section{Sound Ensemble 2: Sonic Representation of Future Possibilities}

The potential for sound to house simultaneous, conflicted meanings was observed in other moments as well. In another ensemble toward the end of Racial Discrepancies, the group members discussed the best way to weave together sound effects, music, and speech. See Figure 2 for display of the layered sounds in the final radio product. In this transition, which leads into the final segment of the documentary, Rowan responds to Erin and Mahmud's suggestion to move their teacher's interview clip to the end of the documentary. Upon listening to the interview clip several times, Erin and Mahmud feel the interview clip, from a teacher who is well known and respected by many students, would work well as a closing thought for the documentary. As prelude to this piece of dialogue, Rowan layers three sound elements: jazz piano music, a hallway conversation sound effect, and a repeated use of the door sound effect. The piano music plays for 15 seconds before the 20-second interview dialogue and then continues playing for an additional 15 seconds after the dialogue, thus playing for a total of 50 seconds, a substantial portion of the seven-minute documentary.

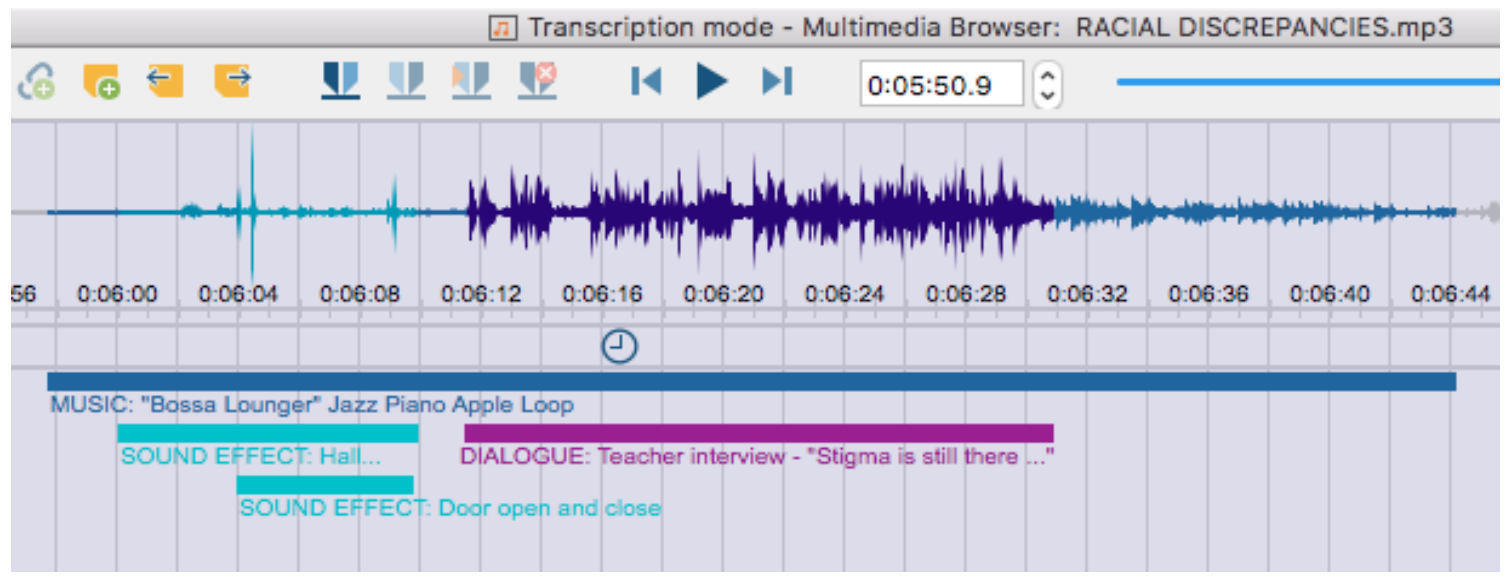

Figure 2. Sound ensemble \#2 representing multiple purposes (This figure illustrates the various layers of sound and music being used in a single transition of the radio documentary).

In this particular scene, the teacher's dialogue states that, while academic tracking may be decreasing at the school, there is still a racial stigma related to enrolling in certain classes. Taken alone, this dialogue can be seen as confirming the group's initial observations about race and course selection, that race does 
impact course selection. In light of the group members' respect for the teacher in the interview, Rowan uses music and sound to shape the tone of the dialogue in two distinct, yet complementary, ways.

In an interview conducted at the time of editing this particular transition, Rowan describes this specific piece of jazz piano music as "swelling" and "bolstering" the words of the teacher in order to present an uplifting and hopeful tone for the documentary. While Rowan shares that he personally does not find the teacher dialogue to be that optimistic, he wants the radio documentary, as a whole, to be more hopeful and present his school as offering equal opportunity and access to students, not biased according to race. To accomplish this, he layers the dialogue with what he describes as "uplifting" piano music and includes a time interval where just the music plays, giving the music, as Rowan describes, "the last word" or lasting impression of the documentary. Through use of the hallway conversation and swelling piano music, he attempts to make more believable and "uplifting" the final message of hope in the documentary-the message that, while race may be seen as a determining factor in school achievement, the situation is changing and may, in the future, not matter when selecting classes.

For Mahmud and Erin, however, the sound design in this specific transition serves a different purpose. While they both agree that placement of the teacher voice builds authority and presents "more knowledge and wisdom" on the issue, they believe strongly that the sound effect of hallway conversation was intended to represent the diversity of voices in the school. Beyond diversity, the student voices were meant, according to Mahmud, to suggest that people may choose courses depending on their comfort levels. As Mahmud further elaborates, "You feel more comfortable being with your own kind." So while Rowan listened and relistened, making sound selections to downplay the impact of race in course selection, Mahmud and Erin interpreted the same sound effects and decisions as emphasizing the cultural and linguistic diversity of their school.

In this scenario we hear young people practicing a form of close, critical listening, in which they listen and re-listen to the sounds, to their own voices and ideas as texts to be examined. Through addition and deletion of specific sound effects they revise their representations. Similar to Green's (2016) discussion of "air-shifting," in which the radio elements of music, voice, and sound are leveraged for purposes of reflection and critique, Rowan, Mahmud, and Erin are able to harness the representational potentials of music and sound in ways that question and challenge the meaning of words alone. The sound ensemble space allows for the coexistence of these multivoiced, and at times, discordant views, yet while collaborating with others, they are still able to form distinct engagements with the sounds in ways that push and probe their own thinking. For Rowan, it is the revision of music choices and sound effects. For Erin it is the manipulation of volume levels. For Mahmud, it is the inclusion of diverse voices and languages, hoping to position the ethnic and linguistic diversity of their school as an asset to be celebrated.

In these instances, the listening and sound revisions operate as critical practices that afford the group opportunities to both notice and interrogate their own perspectives. These sound revisions also forge pathways to imagine 
alternative futures that do not match their current realities. In turn they are invited to take responsibility and write a different future into being.

\section{Discussion: Sonic Landscapes for Cultural Dexterity}

Above we illustrate two sonic ensembles in which sound is harnessed as a vehicle for participation, pluralism, and personal knowledge production through struggle. In both cases, different elements of sound are harnessed to express different meanings and social actions. While in some cases there are conflicting interpretations among group members surrounding the sound decisions and purposes, these struggles become an invitation to sort through meaning. In other words, the spaces of collaborative sound design become spaces to position, bend, and stretch ideas. Consistent with other studies that have found media production and music as potent vehicles for authoring agentive selves amid competing discourse (Hull \& Katz, 2006; Brader \& Luke, 2013), this study shows the mediational potentials of sound to negotiate and articulate diverse social positions.

Similar to other practices of critical digital literacies (Avila \& Pandya, 2013), these personalized engagements with sound exemplify moves and assertions that create "digital texts that interrogate the world" (p. 3). Furthermore these sonic engagements, while conflicted in meaning, occur simultaneously in ways that invite opportunities to practice the "cultural dexterity" aimed for through CSP (Alim \& Paris, 2017, p. 3). Looking specifically at interrogation as it occurs in sound, we see Mahmud, Rowan, and Erin using sound to gain mobility and dexterity in spaces that may otherwise be socially confining.

After reviewing the sound and media revisions made by Erin, Mahmud, and Rowan as well as the sound and media decisions observed in several other youth composing with sound and media, we present here three key moves of social assertion. Described below as sonic punctuation, sonic appropriation, and sonic oscillation, these movements present sound as a resource to claim mobility, revise, and resist the limited trajectories laid out by pre-existing identities. Sonic punctuation represents the use of sound to assert a certain stance or identity position related to an issue. Sonic appropriation, on the other hand, is the use of sound to align meanings of words, or in other cases images, with a preferred tone or mood. Such shifts in tone and meaning serve to complicate monolithic identities. Sonic oscillation then represents the use of sound to deliberately toggle back and forth between the here and there, allowing for an intentional pluralism or mestiza of social positioning

For Mahmud, the sound decisions in the documentary exemplify a form of sonic punctuation, to assert his academic legitimacy in the class and the school. In a post-production interview, Mahmud describes how the English course was his first honors course, and that this was important to his family. He also describes at length the sacrifices his family has made to allow him to focus on school. Much like Mr. Mohammed states in the documentary, Mahmud views class selection not as a racial issue but as one of family expectation, in which family needs supersede personal wishes. In this sense, Mahmud uses elements of sound much like a 
period or exclamation point to announce and reiterate his stance as academic achiever in the class, thus fulfilling his family's expectations.

For Rowan, the sound design choices represent a form of sonic appropriation in that they seek to deliberately influence the credibility of certain perspectives. In one case Rowan describes his use of music to "cover up" or weaken ideas. In another transition he uses sound effects and music to idealize or "bolster" ideas. In both cases he uses sound to challenge or appropriate meanings. While Rowan claims that these editing decisions were made to protect the work, some may hear these sound choices as minimizing or overlooking the impacts of institutional racism. However, some may "hear" and "see" the sound choices, or sonic appropriations, as Rowan's attempts to reconcile his own social positioning through a deliberate distancing of himself from the arrogance and privilege he feels are represented by one of his peers.

For Rowan, finding a social position that is outside discourses of racism, White privilege, and color blindness may not be easy. As the son of a German immigrant mother and Native American father, Rowan does not easily affiliate with available social positions. Instead he must forge a new position, that of an ally, suggesting that, while he may be perceived as White, he is not rich, not privileged, and not racist. It is through the multimodal struggle of sound design that he is afforded the ability to perform multiple social positions, that of media competent and social ally, a practice some are calling "creative identification" (Jupp \& Slattery, 2010). Such dynamic performances of social assertion attempt to challenge White privilege through experiences that avoid "once-and-for-all essentialisms" of racial identity (p. 431). For Rowan, the sonic appropriations of meaning also allow for a social dexterity to position himself as both White and biracial, both privileged and not, both resistant and ally.

Similar to Rowan, Erin also uses sound elements to disrupt stereotypic representations of race. For Erin, the sound modifications exhibit a form of sonic oscillation in that they allow her to move fluidly between already established identity positions. In post-production interviews, Erin is quick to acknowledge that her White friend, Ethan, may not realize how difficult others' lives are but that she still wanted the radio documentary to avoid stereotypical representation. Furthermore, she notes that as a student of color, she enrolls in advanced courses not to be with others who share her worldview, but rather because "they are at our level." In this sense, one might see Erin using the mediational powers of sound to move back and forth, or oscillate, between different social positions. This mobility, made possible by sound, allows her to pivot between academic achiever, supportive peer, and African American female, granting her space and time for social deliberation, to contemplate meaning and forge new understandings. For Erin, like Rowan and Mahmud, sound design provided spaces to navigate within and beyond community and school-based identities, a critical multimodal practice that is both nuanced in expression and agile in cultural affiliation.

Such critical moves are worthy of further investigation. In addition to forging spaces for cultural agility, this study calls for pedagogies that teach what sound means and how sound is tied to other literacies and social change. The soundbased pedagogies described above welcome students' socio-cultural contributions 
in ways that allow for productive co-existence of conflicting views. More opportunities to listen critically to and compose with sound are needed to promote and expand students' repertoires of sound-based critical digital literacies.

\section{Conclusion}

Moving forward in our understandings of multimodal composition as it relates to sound, we are able to take the media practices of Rowan, Erin, and Mahmud as examples of how the subtlest of multimodal choices, such as the layering of sound effects with music, can have significant impacts on media producers' social stance and deliberation of perspectives. In illustrating the emergence of these critical moves, it is important to note that adolescents crave meaningful engagement with social issues like race and privilege, yet at the same time seek multimodal routes of expression to explore and experiment with social positioning around these topics.

Although beyond the scope of this particular study, further research into how, when, and why media users opt to appropriate mediational means for purposes of critical revision is needed. Future research might examine classroomlearning situations that invite multimodal, collaborative composition and ask the following questions: (a) how do such spaces open back channels for multivocal exploration and deliberation of social issues, and (b) how do such back channels forge transformative, sustaining cultural practices in classroom spaces? Such explorations might better illustrate both the expressive and social mobility affordances of sound.

In the spirit of Ceraso's (2014) call for more attention to the "sonic experiences" of learning, students, teachers, and researchers must continue to practice close listening for the multivocal properties of multimodal composition. Moreover, we must continue to make visible the experiences of youth as they harness different elements of sound to stake positions within larger social texts. In particular we must pay attention to how sound and music, although not in plain sight, can shift representations of truth in ways that open spaces for the cultural dexterity needed to thrive in local and global contexts. Perhaps it is with classroombased collaborative sound design that such multicultural imaginaries can begin.

\section{Notes}

1. All proper names used are pseudonyms to protect the participants involved in this study as per guidelines stated in Interval Review Board (IRB) approval. 


\section{References}

Ahern, K. (2013). Tuning the sonic playing field: Teaching ways of knowing sound. Computers and Composition, 30, 75-86.

Alim, H, \& Paris, D. (2017). What is culturally sustaining pedagogy and why does it matter? In D. Paris \& H. S. Alim (Eds.), Culturally sustaining pedagogies: Teaching and learning for justice in a changing world (pp.1-21). New York, NY: Teachers College Press.

Anzaldúa, G. (1987). Borderlands: The new mestiza = La frontera. San Francisco, CA: Spinsters/Aunt Lute.

Ávila, J., \& Pandya, J. (2013). Critical digital literacies as social praxis: Intersections and challenges. New York, NY: Peter Lang.

Ashmawi, P., Sanchez, E., \& Carmona, J. (2015). Testimonialista pedagogues: Testimonio pedagogy in critical multicultural education. International Journal of Multicultural Education, 20(1), 67-85.

Bezemer, J., \& Kress, G. (2008). Writing in multimodal texts: A social semiotic account of designs for learning. Written Communication, 25(2), 166-195.

Brader, A., \& Luke, A. (2013). Documenting youth engagement with digital music production in Australia. In K. Jocson (Ed.), Cultural transformations: Youth and pedagogies of possibility (pp. 203 - 226). Cambridge, MA: Harvard Education.

Buckley-Marudas, M. F. (2016a). Literacy learning in a digitally-rich humanities classroom. Journal of Adolescent and Adult Literacy, 59(5), 551-561.

Buckley-Marudas, M. F. (2016b). "Truth" interrupted: Leveraging digital media for culturally sustaining education. Multicultural Learning and Teaching, 12(2).

Brownell, C., \& Wargo, J. (2017). (Re)educating the senses to multicultural communities: Prospective teachers using digital media and sonic cartography to listen for culture. Multicultural Education Review, 9(3), 201214.

Case, A., \& Ngo, B. (2017). "Do we have to call it that?" The response of neoliberal multiculturalism to college antiracism efforts. Multicultural Perspectives, 19(4), 215-222.

Ceraso, S. (2014). (Re)Educating the senses: Multimodal listening, bodily learning, and the composition of sonic experiences. College English, 77(2), 102-123.

Chavez, V., \& Soep, E. (2005). Youth radio and the pedagogy of collegiality. Harvard Educational Review, 75(4), 409-434.

Chignell, H. (2009). Key concepts in radio studies. Los Angeles, CA: Sage. 
Comstock, M., \& Hocks, M. (2006). Voice in the cultural soundscape: Sonic literacy in composition studies. Computers and Composition Online. Retrieved from http://cconlinejournal.org/comstock_hocks/index.htm

Darder, A. (1991). Culture and power in the classroom: A critical foundation for bicultural education. New York, NY: Bergin \& Garvey.

Dockter, J., Haug, D., \& Lewis, C. (2010). Redefining rigor: Critical engagement, digital media, and the new English/language arts. Journal of Adolescent and Adult Literacy, 53(5), 418-420.

Doerr-Stevens, C. (2015). 'That's not something I was, I am, or am ever going to be': Multimodal self-assertion in digital video production. E-Learning \& Digital Media: Special Issue on Digital Media Production, 12(2), 164-182.

Doerr-Stevens, C. (2016). Drawing near, pushing away: Critical positioning in multimodal composition. Pedagogies: An International Journal, 11(4), 335353.

Doerr-Stevens, C. (2017). Multimodal exploration of civic stance in the English language arts classroom. English Teaching: Practice and Critique, 16(1), 628.

Gershon, W. S. (2017). Sound curriculum: Sonic studies in educational theory, method, and practice. New York, NY: Routledge.

Green, K. L. (2013), "The way we hear ourselves is different from the way others hear us", Exploring the Literate Identities of a Black Radio Youth Collective. Equity \& Excellence in Education, 46(3), 315-326.

Green, K. L. (2016), "Black 'youth speak truth' to power: literacy for freedom, community radio, and civic engagement." In Greene, S., Burke, K. \& McKenna, M. (Eds), Youth voice, public spaces, and civic engagement (pp. 189-209). New York, NY: Routledge.

Hull, G., \& Katz, M. (2006). Crafting an agentive self: Case studies of digital storytelling. Research in the Teaching of English, 41(1) 43-81.

Hull, G., \& Nelson, M. (2005). Locating the semiotic power of multimodality. Written Communication, 22(2), 224-261.

Jenkins, H. (2018). Millenials, new media, and social change (Part Two). Retrieved from http://henryjenkins.org/blog/2017/12/19/millenials-new-media-andsocial-change-part-to?rq=civic\%20imagination

Jupp, J., \& Slattery, P. (2010). Committed White male teachers: Toward creative identifications and a "second wave" of White identity studies. Curriculum Inquiry, 40(3), 454-474.

Ladson-Billings, G. (2009). The dreamkeepers: Successful teachers of African American children. San Francisco, CA: Jossey-Bass.

Latina Feminist Group. (2001). Telling to live: Latina feminist testimonios. Durham, NC: Duke University Press. 
Liou, D. (2016). Fostering college-going expectations of immigrant students through the sympathetic touch of school leadership. Multicultural Perspectives, 18(2), 82-90.

Mills, K., Ulsworth, L., \& Exley, B. (2018). Sensory literacies, the body, and digital media. In K. Mills, A. Stornaiuolo, A. Smith, \& J. Pandya, (Eds.), Handbook of writing, literacies and education in digital cultures (pp. 26-36). New York, NY: Routledge.

Nelson, M., \& Hull, G. (2008). Self-presentation through multimedia: A Bakhtinian perspective on digital storytelling. In K. Lundby (Ed.), Digital storytelling, mediatized stories (pp.123-144). New York, NY: Peter Lang.

New London Group (2000). A pedagogy of multiliteracies: Designing social futures. In B. Cope, \& M. Kalantzis (Eds.) Multiliteracies: Literacy learning and the design of social futures (pp. 9-38). London, UK: Routledge.

Ngo, B., Lewis, C., \& Maloney Leaf, B. (2017). Fostering sociopolitical consciousness with minoritized youth: Insights from community-based arts programs. Review of Research in Education, 41, 358-380.

Nieto, S. (1992). Affirming diversity: The sociopolitical context of multicultural education. New York, NY: Longman.

Norris, S., \& Jones, R. (2005). Discourse in action: Introducing mediated discourse analysis. London, UK: Routledge.

Paris, D., \& Alim, H. (2014). What are we seeking to sustain through culturally sustaining pedagogy? A loving critique forward. Harvard Educational Review, 84(1), 85-100.

Patton, M. Q. (2001). Qualitative evaluation and research methods (3rd ed.). Newbury Park, CA: Sage.

Ranker, J. (2014). The emergence of semiotic resource complexes in the composing processes of young students. Linguistics and Education, 25, 129-144.

Santo, R. (2013). Hacker literacies: User-generated resistance and reconfiguration of networked publics. In J. Avila \& J. Z. Pandya (Eds.), Critical digital literacies as social praxis: Intersections and challenges. (pp 197-218). New York, NY: Peter Lang.

Scollon, R., \& Scollon, S. (2003). Discourse in action: Language in the material world. New York, NY: Routledge.

Selfe, C. (2009). The movement of air, the breath of meaning: Aurality in multimodal composition. College Composition and Communication, 60(4), 616-663.

Sleeter, C. E. (2005). Un-standardizing curriculum: Multicultural teaching in the standards-based classroom. New York, NY: Teachers College Press. 
Sleeter, C. E. (2018). Multicultural education past, present, and future: Dialogue and power-sharing. International Journal of Multicultural Education 20(1), 520.

Soep, E. (2006). Beyond literacy and voice in youth media production. McGill Journal of Education, 41(3), 197-213.

Todorova, S. (2015). Dusty but mighty: Using radio in the critical media literacy classroom. The National Association for Media Literacy Education's Journal of Media Literacy Education, 6(3), 46-56.

Van Leeuwen, T. (1999). Speech, music, sound. London, UK: Macmillan.

Wohlwend, K. (2009). Mapping multimodal literacy practices through mediated discourse analysis. In K. Leander, D. Rowe, R. Jimenez, D. Compton, D. Dickinson, Y. Kim, \& V. Risko (Eds.), Fifty-eighth yearbook of the National Reading Conference (pp. 66-81). San Antonio, TX: National Reading Conference.

Wohlwend, K., \& Lewis, C. (2011). Critical literacy, critical engagement, digital Technology: Convergence and embodiment in global spheres. In D. Lapp \& D. Fisher (Eds.), The handbook on teaching English and Language Arts ( $3^{\text {rd }}$ ed.) (pp. 188-194). New York, NY: Routledge.

\section{Author Contact}

Candance Doerr-Stevens: doerrste@uwm.edu

Department of Teaching and Learning, University of Wisconsin, Milwaukee, 2400 E. Hartford Avenue, Milwaukee, WI 53211

Molly Buckley-Marudas: m.buckley67@csuohio.edu

Department of Teacher Education, Cleveland State University, 2121 Euclid Avenue, Cleveland, $\mathrm{OH} 44115$ 